\title{
Representações sociais da física newtoniana: um estudo com professores do ensino médio
}

\author{
Social representations on newtonian's physics: a study with high \\ school teachers
}

\author{
Roberto Gonçalves Barbosa ${ }^{1}$, Marta Bellini², Alcina Maria Testa Braz da Silva ${ }^{3}$
}

\section{Resumo}

Este trabalho tem como finalidade apresentar os resultados do estudo das Representações Sociais que professores de Física da cidade de Maringá e região adjacente elaboram sobre a Física Newtoniana. O tratamento dos dados da pesquisa se deu pela Teoria da análise de conteúdo da Bardin, que nos permitiu compreender as reconstruções e ressignificações que os docentes fazem sobre a Física newtoniana em situações de ensino. Metodologicamente, foi aplicado um questionário com duas partes a oito professores que ministram a disciplina Física no ensino médio de escolas públicas. Constatou-se que, entre oito professores, um representava a Física newtoniana recorrendo à Física de Newton. Os outros sete professores se utilizaram de elementos do cotidiano para ressignificar a Física de Newton, em um processo que envolve desfalque, distorção e suplementação do objeto social investigado.

Palavras-chave: Representações sociais. Ensino de Física. Física de Newton. Conhecimento escolar. Conhecimento científico.

\begin{abstract}
This paper has the purpose to present the study results of Social Representations on Newtonian's Physics, which Physics teachers from Maringá and neighboring cities have created. The interpretation of research data was carried out through Bardin content analysis theory that allowed the studying team to understand the reconstruction and redefinitions that teachers make on Newtonian's physics while teaching. As methodology, one questionnaire was applied in two parts. Eight physics teachers from public high schools answered it. It was found that among eight teachers, one represented the Newtonian's physics using to Newton's Physics. The other seven teachers used daily elements to redefine Newton's physics in a process that involved embezzlement, distortion and supplementation of the investigated social object.
\end{abstract}

Keywords: Social representation. Teaching of Physics. School knowledge. Scientific knowledge.

\footnotetext{
${ }^{1}$ Doutorando na Universidade Estadual de Londrina - Programa de Pós graduação em Ensino de Ciências e Educação Matemática e também pela University of Massachusetts/Amherst - EUA. Atualmente professor da Secretaria de Estado da Educação do Paraná. E-mail: betofisica@yahoo.com.br

${ }^{2}$ Doutora em Psicologia Social pela Universidade de São Paulo. É professora associa do Departamento de Fundamentos da Educação da Universidade Estadual de Maringá. Email: martafridakahlo@gmail.com

${ }^{3}$ Doutora em Educação pela Universidade Federal do Rio de Janeiro/ FE-UFRJ, Pós-Doutorado na Faculdade de Educação da Universidade Federal de Minas Gerais/FAE-UFMG e atualmente é docente e pesquisadora do Programa de Pós-Graduação stricto sensu em Ensino de Ciências do Instituto Federal de Educação, Ciência e Tecnologia do Rio de Janeiro. Universidade Salgado de Oliveira, Niterói, Brasil. E-mail: alcinamaria@terra.com.br
} 


\section{Introdução}

Apresentamos, neste artigo, o estudo realizado em 2006 com professores de Física da rede pública de Maringá e região adjacente sobre as Representações Sociais da mecânica newtoniana, com o objetivo de analisar suas práticas didáticas. Mais especificamente, procurou-se compreender como os docentes recriavam os conceitos de força, massa e inércia aos seus alunos em situação ensino.

A mecânica de Newton é um conhecimento científico que, ao ser transposto para a sala de aula, torna-se um conhecimento escolar, como argumenta Lopes (2000, p.155) "conhecimentos que não têm por base apenas conhecimentos científicos, nem sua lógica". Os conhecimentos escolares são saberes recontextualizados pelas dimensões da didatização e da axiologização exigidos pela escola. Desse modo, os saberes científicos incorporam as práticas sociais de referência que são, segundo Lopes (2000, p.155), "as atividades sociais de referências diversas de pesquisa, produção, engenharia, bem como atividades domésticas e culturais".

Nessa passagem dos conhecimentos científicos aos escolares, atuam as ressignificações, ou melhor, as Representações Sociais, resultantes das interações sociais que ocorrem no cotidiano, nas relações em família, entre amigos, na escola, no trabalho e no lazer. Nas diversas relações sociais, o sujeito, no caso, o professor, vivencia uma série de situações que repercutem em sua conduta. Em sua trajetória, desde sua experiência acadêmica até a sala de aula, entrará em contato com modelos e representações que influenciarão seu modo de ser professor.

No sentido de pensar a prática docente do professor de Física e suas representações da mecânica de Newton no ensino escolar, tomamos por referencial o olhar trazido pela Teoria das Representações Sociais, segundo a abordagem proposta por Moscovici. Essa Teoria consiste em um domínio de pesquisa que busca compreender o modo pelo qual o significado é atribuído ao objeto; como os atores sociais interpretam o universo social; como ocorre a orientação das condutas e relações sociais em função das representações elaboradas; como estas representações são integradas ao sistema cognitivo pré - existente dos sujeitos sociais (JODELET, 2001). Segundo Semin (2001, p. 208), uma Teoria que "busca uma posição ou perspectiva por meio da qual um indivíduo ou um grupo observa e interpreta os acontecimentos e as situações cotidianas".

De acordo com Jodelet (2001), as representações sociais são Teorias socialmente criadas e operantes, relacionam-se com a construção da realidade cotidiana, com as condutas e comunicações que se desenvolvem neste contexto e, também, com a vida e a expressão dos grupos no seio dos quais elas são elaboradas.

Nesta perspectiva, nosso trabalho foi definido, segundo as seguintes questões norteadoras: quais as Representações Sociais dos conceitos da Física newtoniana estão presentes nas situações de ensino dos professores de Física? Como os docentes resignificam conceitos como força, massa e inércia no contexto do ensino?

\section{A Teoria Das Representações Sociais: uma Teoria para a Investigação na Área de Ensino de Ciências}

A expressão representação social foi mencionada pela primeira vez no trabalho de Serge Moscovici, em 1961, na obra, "Psicanálise: sua imagem e seu público" (SÁ, 1995, p.19). Nessa obra, Moscovici apresentou um estudo no qual se propõe compreender de que forma a psicanálise, ao sair dos grupos fechados e especializados, adquire uma nova significação pelos grupos populares (ALEXANDRE, 2001, p.124). O conceito de representação social surgiu tendo por base o conceito sociológico de representações coletivas de Durkheim (apud MOSCOVICI, 2001), a partir da elaboração feita por Moscovici, em seu texto seminal. 
A representação coletiva é 'homogênea e vivida por todos os membros de um grupo, da mesma forma que partilham uma língua'; tendo 'por função preservar o vínculo entre eles, prepará-los para pensar e agir de modo uniforme. Ela é coletiva, por isso e também porque perdura pelas gerações e exerce uma coerção sobre os indivíduos, traço comum a todos os fatos sociais' (MOSCOVICI, 2001, p. 47).

Entretanto, duas críticas à concepção durkheimiana foram relevantes para a proposta de Moscovici (2001):

1. Em primeiro lugar, a falta de uma preocupação em explicar a origem da generalidade de fenômenos que o conceito de representação coletiva engloba: a ciência, a religião, os mitos, a ideologia, entre outros fenômenos, quer sejam sociais ou psíquicos.

2. Além disso, a questão da ausência de dinâmica que o conceito de Representações coletivas apresenta não o torna adequado a um estudo de sociedades complexas como a nossa, onde existem uma pluralidade de sistemas envolvidos (políticos, filosóficos, religiosos, entre outros) e uma alta rotatividade de fluxo de representações.

Como afirmou Guareschi (1997, p.196):

Moscovicitinha consciência que o modelo de sociedade de Durkheim era estático e tradicional, pensado para tempos em que a mudança se processava lentamente. As sociedades modernas, porém, são dinâmicas e fluidas. Por isso, o conceito de coletivo apropriavase melhor àquele tipo de sociedade, de dimensões mais cristalizadas e estruturadas. Moscovici preferiu preservar o conceito de representação e substituir o conceito coletivo, de conotação mais cultural, estática e positivista, pelo social: daí o conceito de Representações Sociais.

Para Moscovici (2001), as representações sociais resultam da interação entre sujeito e sistema, ou seja, seu entorno social. Todas as culturas que conhecemos constroem instituições e normas que orientam, de um lado, a individualização e, de outro, a socialização. Como as Representações Sociais são sempre partilhadas dentro de um grupo social, fica assegurada a possibilidade de coexistência entre indivíduo e sociedade. No entanto, temos que responder às questões: Como criamos essas representações? De que maneira elas influenciam nossas ações? Para iniciar as respostas, podemos dizer que, ao nos confrontarmos com diferentes objetos, nós os recriamos em nossa mente, ancoramo-nos em crenças, valores e ideologias que são expressas por gestos, palavras e silêncios. Em um universo de comunicação, criamos e transmitimos nossas representações, e o que nos parecia estranho, torna-se comum, quase normal.

Por exemplo, como é curiosa a maneira pela qual nós, modernos, pensamos a respeito do nosso mundo! $\mathrm{E}$ como é nova, também, a cosmologia subjacente a nossos processos mentais tem apenas três séculos de idade - uma simples criança na história do pensamento - e, no entanto, nos apegamos a ela com o mesmo zelo intranquilo com que um jovem pai afaga seu bebê recém-nascido. Tal como ele, somos bastante ignorantes a respeito da natureza precisa; contudo, tal como ele, acreditamos candidamente que ela nos pertence e permitimos que ela exerça um controle sutil, abrangente e sem restrições sobre nosso pensamento (BURTT, 1983, p. 9).

Mas, como são geradas as representações sociais? Moscovici classifica dois mecanismos geradores de representação: a ancoragem e a objetivação. Ancorar e objetivar são mecanismos que transformam o não familiar em familiar, primeiramente, transferindoos à nossa própria esfera particular, onde nós somos capazes de compará-los e interpretá-los; e, depois, materializando-as, recriando, entre outras coisas, o que nós podemos ver e tocar, e, consequentemente, controlar. Para Moscovici (2003), ancorar é classificar, dar nome a alguma coisa, reduzi-la a categorias e imagens comuns, colocá-la em um contexto familiar (MOSCOVICI, 2003, p.61). Jodelet (1984 apud SÁ, 1995), afirma que a ancoragem consiste na integração cognitiva do objeto representado - sejam ideias, acontecimentos, pessoas, relações, etc. - em um sistema de pensamento social, preexistente e nas transformações implicadas.

Conceitos como força, massa, inércia são naturais ao meio científico e, também, ao nosso dia a dia escolar no ensino da Física. No entanto, quando solicitados (de acordo com o contexto vivido), nós selecionamos em nossa mente. Quando falamos da Força Peso, por exemplo, os alunos geralmente associam este conceito a uma característica intrínseca do objeto - eu vou me pesar! - com objetivo de trazer o conceito à sua realidade. Tais 
sujeitos classificam o conceito em sua rede de significações, isto é, "procedem recorrendo ao que é familiar, para fazerem uma espécie de conversão da novidade: trazê-lo ao território conhecido da sua bagagem nocional, ancorar aí o novo, o desconhecido, retirando-o da sua navegação às cegas pelas águas do não familiar" (ARRUDA, 2002, p. 136).

Uma investigação nesse percurso das representações sociais é a de Pitombo e Silva (2006). Nesta, os autores expõem como constataram a ancoragem dos alunos na palavra fogo, no ensino da Química acerca do tema queima e combustão, estudado por alunos das séries finais do ensino fundamental e médio (oitavas e terceiras séries). Os estudiosos concluíram que os alunos compreendiam o conceito de combustão, por meio da palavra fogo, ou seja, por determinada noção social preexistente (PITOMBO; SILVA, 2006). Dessa forma, o conceito de combustão ficava deformado por essa ideia preexistente. Os alunos compreendiam combustão como apenas a queima de objetos em que tudo desapareceria.

A objetivação, outro processo de formação das Representações Sociais, consiste em uma operação imaginária e estruturante, pela qual se dá uma forma - ou figura - específica ao conhecimento acerca do objeto, tornando concreto, quase tangível, o conceito abstrato, materializando a palavra (JODELET apud SÁ, 1995, p.39). Para Moscovici (2003, p. 71), objetivar é descobrir a qualidade icônica de uma ideia, ou ser impreciso; reproduzir um conceito em uma imagem, "porque, desde que nós pressupomos que as palavras não falam sobre nada, somos compelidos a ligá-las a alguma coisa, a encontrar equivalentes não verbais". Tomando como exemplo a argumentação de Moscovici (2003, p, 71), no campo da construção do conhecimento cientifico:

O físico inglês Maxwell disse, certa vez, que o que parecia abstrato a uma geração se torna concreto para a seguinte. Surpreendentemente, Teorias incomuns, que ninguém levava a sério, passam a ser normais, críveis e explicadoras da realidade, algum tempo depois. Como um fato tão improvável, como o de um corpo físico produzindo uma reação a distância, em um lugar onde ele não está concretamente presente (campo gravitacional, campo eletromagnético), pode transformar-se, menos de um século depois, em um fato comum, inquestionável - isso é, ao menos tão misterioso, como uma descoberta e de consequências muito maiores. Essa domesticação é o resultado da objetivação. Isto é, ela une a ideia de não familiaridade com a de realidade, torna-se a verdadeira essência da realidade. Percebida primeiramente como um universo puramente intelectual e remoto, a objetivação aparece, então, diante de nossos olhos, Física e acessível (MOSCOVICI, 2003, p.71).

Neste cenário de discussão epistemológica, estar diante de um objeto desconhecido, ou, ainda, abstrato (imaterial), obriga-nos a buscar, em nossa rede de significações, uma figura que se encaixe, para que possamos trazê-la para o nosso universo paradigmático. Moscovici (2003) distingue dois universos conceituais: o consensual e o reificado. Segundo o universo consensual, a sociedade é vista como um grupo de pessoas que são iguais e livres, cada um com possibilidade de falar em nome do grupo e sob seu auspício. Dessa maneira, presume-se que nenhum membro possua competência exclusiva, mas cada qual pode adquirir toda competência que seja requerida pela circunstância: médicos, políticos, professores - mediado pela conversação - em bares, clubes, praças (MOSCOVICI, 2003, p.50). Já na perspectiva do universo reificado, a sociedade é entendida como um sistema de entidades sólidas, básicas, invariáveis, que são indiferentes à individualidade e não possuem identidade. Essa sociedade ignora a si e as suas criações, que ela vê somente como objetos isolados, tais como, pessoas, ideias, ambientes e atividades (MOSCOVICI, 2003, p.51). Neste meio, a fala é restrita, quer dizer, o que determina o que se fala é o grupo do qual se faz parte: médicos, professores, psicólogos; especialistas, cada qual em sua área.

Desse modo, os universos representacionais classificados por Moscovici referem-se ao conhecimento científico, quando se fala de universo reificado. Nesse universo, a verdade final tem que passar por uma série de barreiras - conceituais e experimentais. Já no universo consensual, o 
conhecimento é produzido pela sociedade, de um modo geral, em bares, escolas, praças e cafés, nos quais as discussões são descomprometidas, mas não menos importantes, sob o ponto de vista psicossociológico.

\section{Ensino de Física: Por que um Olhar Psicossocial?}

A Física como qualquer outro conhecimento é elaborado socialmente, localizado historicamente no espaço e no tempo; é assim que se torna uma disciplina escolar e pode ser transmitida aos alunos. No entanto, dentre os seus inúmeros difusores (livros, revistas, etc.), temos os professores que, durante toda a vida escolar e profissional, constroem seu saber docente, que tem, na experiência da sala de aula, a fonte mais valorizada por eles. Tal saber adquire especificidades, em função da disciplina com a qual trabalham e das relações interpessoais que desenvolvem na convivência com alunos e, ao longo da própria vida no magistério (QUEIROZ, 2001, p.86). Nesse aspecto, a Teoria das Representações Sociais pode ser uma ferramenta adequada para compreensão dos sistemas simbólicos, principalmente de conceitos socialmente construídos e difundidos pelos professores no interior das escolas.

O trabalho de Braz da Silva (1998), fazendo uso da Teoria das Representações Sociais, investigou os elementos do campo da Representação Social sobre Ciência Física apresentado por professores que ministravam a disciplina nas escolas públicas da cidade do Rio de Janeiro. A pesquisadora estudou a Ciência Física, enquanto objeto social a ser apropriado no processo de constituição de saberes próprios de um grupo social, no caso, o grupo de professores de Física. Desta perspectiva, a relação ensino-aprendizagem requereu um exame psicossocial, no qual todos os atores sociais envolvidos, como agentes da constituição de representações sociais sobre objetos próprios da educação escolar - Teorias, conceitos, por exemplo - constituíam o que podemos denominar saber escolarizado. Este saber consiste na produção e negociação de significados.

No que diz respeito ao ensino da Física newtoniana, Braz da Silva (1998) observou o ensino de uma Física desfalcada de sua Geometria. Nesse espaço lacunar, entra a Física do cotidiano. Explicando melhor, a Física de Newton constitui-se de uma Geometria do espaço. No ensino do modelo newtoniano, Braz da Silva (1998) encontrou uma representação social da ciência Física ancorada na não geometrização do espaço. O que se ensina, então, em termos de Física newtoniana, é uma Teoria que perde seu núcleo teórico-científico e fica alicerçada no senso comum.

Braz da Silva (1998) concluiu, mediante a análise de conteúdo do discurso desses professores, que os elementos categoriais identificados apontavam para a representação social do objeto investigado ensino de Física de Newton - ancorada no realismo ingênuo, a qual se constituía em uma posição hegemônica, em torno de $90 \%$ dos entrevistados. Como diz a autora, a Física de Newton passa de uma visão de mundo sistematizada a um conjunto de noções cotidianas que descaracterizaria a Física de Newton na escola.

Neste âmbito de discussão, a representação social é tanto uma atividade como um resultado que conduz a múltiplas identidades de um mesmo objeto em contextos de pluralidade cultural. A transição do conhecimento proveniente de um círculo científico restrito de especialistas para territórios públicos mais amplos é, muitas vezes, a mesma transição que ocorre entre o pensar com conceitos para o pensar com imagens e mitos (BAUER, 1997, p.232). Tal singularidade deve estar presente nas pautas de discussões, pois a ciência, de um modo geral e a Física de modo particular, como um modo de representação do mundo, é sempre sujeita à reformulação. Por exemplo, a lei da gravitação universal de Newton é uma forma de representar, por 
meio de um modelo matemático, a interação entre corpos celestes, sendo, portanto, uma representação simbólica de um tema científico proveniente de um conjunto de relações entre meio e indivíduo.

\section{Metodologia}

\section{$O$ desenho de pesquisa}

Realizou-se uma pesquisa qualitativa, com coleta de dados efetuada, por meio de um questionário com perguntas abertas sobre a formação dos professores entrevistados e com problemas sobre a Física newtoniana. As etapas da pesquisa foram:

1. Levantamento das escolas públicas estaduais de Maringá e região, no período de julho a agosto de 2006. Após esse mapeamento, foi feito contato com dez professores do Ensino Médio, que ministravam a disciplina Física, com formação em Física, e que estavam trabalhando com a disciplina na época da entrevista. Desses dez professores, oito se dispuseram a colaborar com nosso estudo.

2. Para a etapa de coleta de dados, foram elaboradas oito perguntas relativas aos fundamentos newtonianos, divididas em duas etapas: na primeira, foi solicitado ao docente que respondesse a quatro questões (oralmente), que foram gravadas e transcritas posteriormente; em seguida, pedimos que respondesse a outras quatro questões abertas, utilizando-se de caneta e papel (Anexo 1).

3. A definição do local para a realização das entrevistas foi feita pelo professor, sendo escolhida a própria escola onde ele atuava e/ou na Universidade Estadual de Maringá, onde este estudo foi elaborado e orientado. As entrevistas duraram, em média, de 30 a 40 minutos.

4. O tratamento de dados se deu por meio da análise de conteúdo do livro de Laurence Bardin (1977), Teoria cujas fases de análise correspondem à i) pré-análise, ii) a exploração do material e iii) o tratamento dos resultados, a inferência e a interpretação. Para realizar essa tarefa, examinamos: a) as expressões-chaves (trechos selecionados das entrevistas que melhor descrevem o conteúdo); b) as ideias centrais das falas (são as fórmulas sintéticas que são similares nos diferentes indivíduos) que configuram o núcleo de sentido; c) a ancoragem (são as fórmulas sintéticas que descrevem as ideologias, valores e crença das respostas). A análise encaminhada desta forma nos permitiu pensar as entrevistas como um discurso representativo de um grupo (no caso, os professores de Física). Os elementos identificados são aqueles do campo da representação, na medida em que dão significados a um discurso estruturado.

\section{Os Sujeitos da Pesquisa}

Foram entrevistados oito professores da cidade de Maringá e região, número relativamente pequeno, mas que representa uma parcela significativa de um grupo seleto e homogêneo, no caso, professores de Física com formação acadêmica em Física. Todos graduados na mesma universidade e que ainda ministram aulas em escolas públicas de uma mesma microrregião no estado do Paraná.

\section{O Discurso dos Professores}

Nessa etapa, realizamos uma pré-análise, por meio de uma leitura flutuante, visando à exploração do texto. Primeiramente, foi possível enumerar as frequências de aparições de elementos e/ou conceitos da Física newtoniana, de modo a categorizá-las e, ainda, reafirmar/formular a hipótese de que os docentes reapresentam uma Física muito próxima daquela apresentada em livros didáticos de Física. Segundo Braz da Silva e Mazzotti (1998), as produções discursivas (dos docentes) buscam expor um modo de mediação entre o que se encontra nos livros didáticos e o estudante, ou seja, procuram um ardil para que os alunos alcancem o material exposto no livro didático (BRAZ DA SILVA; MAZZOTTI, 1998). 
Uma primeira evidência da hipótese salientada, Newton sejam aplicáveis, como mostra os quadros verificamos nos exemplos dados pelos professores a seguir. sobre fenômenos e/ou situações em que as leis de

Quadro 1 - Unidades significantes escritas.

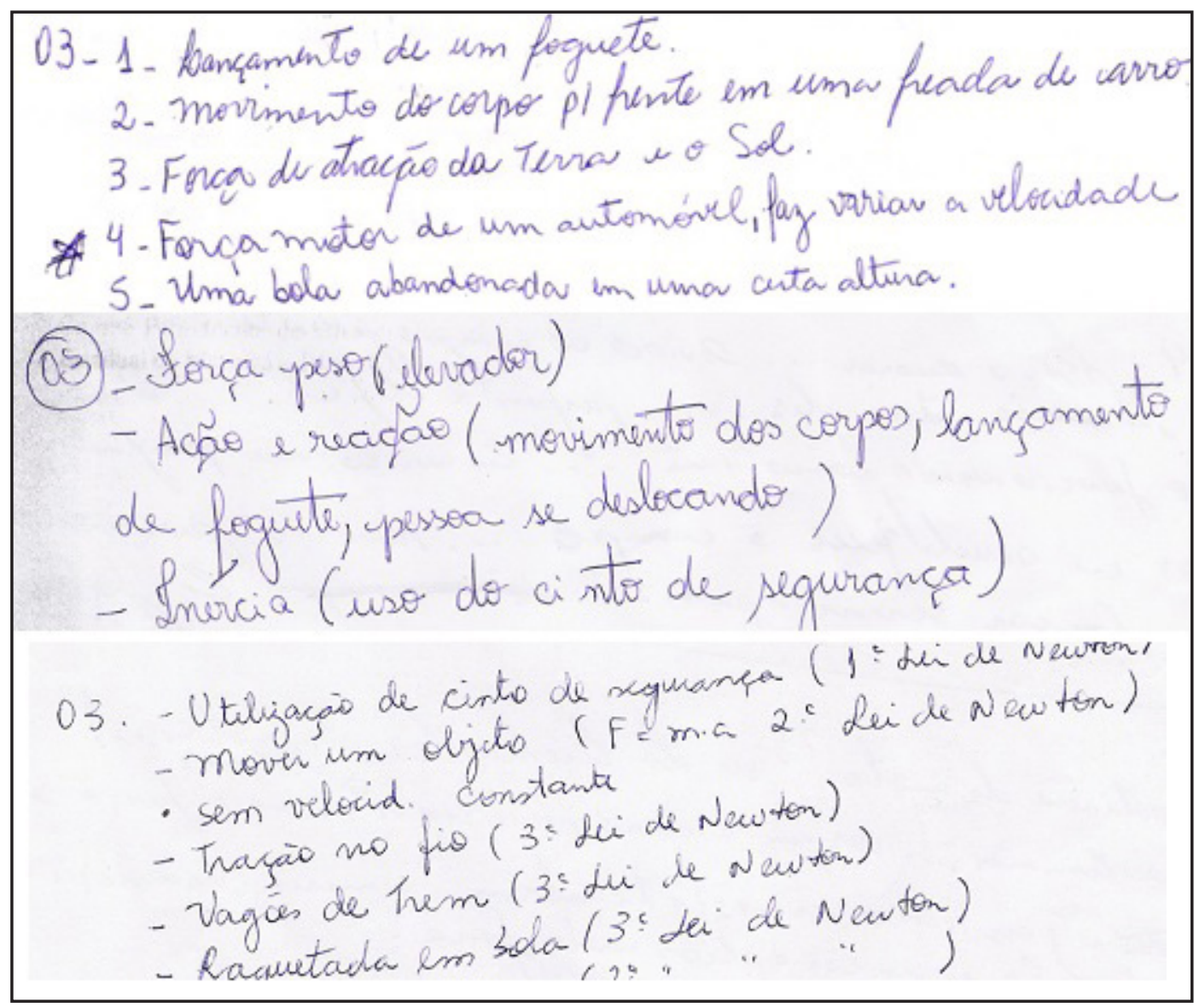

Como podemos observar, os professores reconheceram a presença dos conceitos da Física newtoniana em situações como: o elevador, o cinto de segurança, a queda livre, o lançamento de foguetes, as quais são situações bastante exploradas pelos livros didáticos de Física de autores como Paulo Ueno (editora Ática), Carlos Toscano e Aurélio Gonçalves Filho (editora Scipione), Antônio Máximo e Beatriz Alvarenga (Scipione), utilizados nas escolas públicas do estado do Paraná.

\section{Análise de Conteúdo das Representações dos Professores Sobre a Física de Newton}

Com o objetivo de desvelar como os sujeitos da pesquisa ressignificavam conceitos como massa, força e inércia da mecânica de Newton, realizamos uma análise de conteúdo de abordagem temática dos dados, visando à categorização. Segundo Bardin (1977, p. 105), “a análise temática consiste em descobrir os núcleos de sentido que compõem a comunicação, cuja presença, ou frequência de aparição, podem significar alguma coisa, para o objetivo analítico escolhido".

Por meio de um recorte semântico - de significação - foi possível identificar e classificar três categorias apresentadas nos quadros a seguir. 


\section{Primeira Categoria: Causalidade do Movimento}

Quadro 2 - Unidades significantes oralizadas.

\section{Expressões orais:}

Você impulsionou uma força e o objeto entrou em movimento. Você impulsionou, você dá o impulso, você aplicou a força no corpo, essa força vai fazer com que o corpo adquira uma velocidade, essa velocidade, evidentemente, faz com que ele entre em movimento. Eu acredito que seja explicado pelo impulso, a mão que você está falando, ela deu a Força! Ou seja, um impulso inicial, uma força relativamente grande em um tempo relativamente pequeno... A força ocasionou o movimento. No momento do lance, ele aplica um impulso nessa pedra, saindo da mão da pessoa, pronto! ela não tem mais impulso, ela não tem mais uma força impulsionando, tem a força peso que atua nela.

Quadro 3 - Unidades significantes escritas.

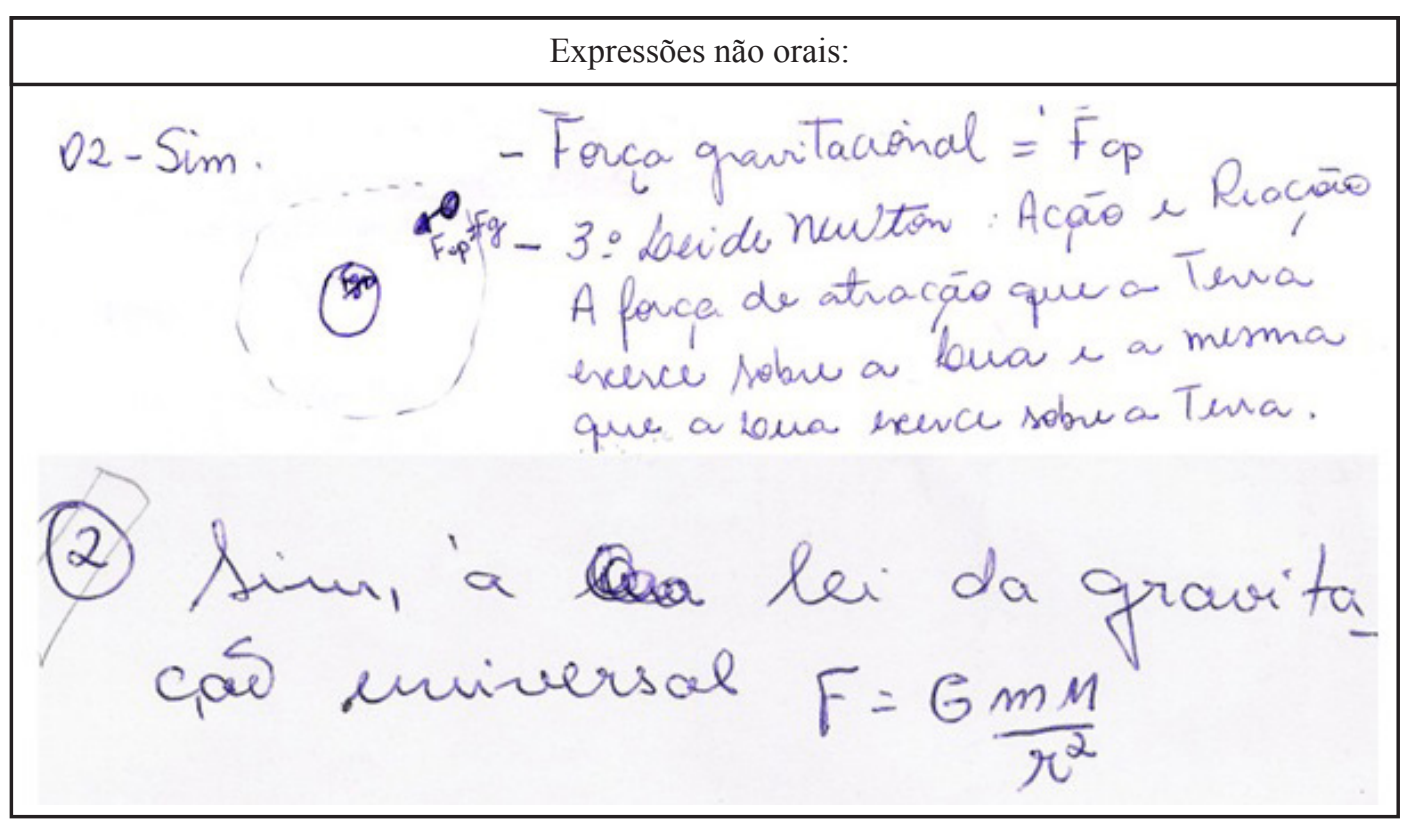

Mediante as unidades de contexto (segmento da mensagem) e das unidades de registro (segmento selecionado), apresentadas no quadro 1 e também por meio das imagens do quadro 2, nota-se que os conceitos de impulso e força são elementos de ancoragem para representar a causa de movimento em objetos. Segundo a Teoria das Representações Sociais, podemos dizer que as expressões - força impulsionando, impulsionou uma força, dar impulso e dar força - são elementos de objetivação, ou seja, um modo pelo "qual se dá forma ao conhecimento acerca do objeto, tornando-o concreto, quase tangível" (JODELET apud SÁ, 1995, p.39). Esses elementos presentes no discurso dos professores mostram que estes mesclam termos científicos e comuns (uniformizante e universalizante), levando ao que Lopes chama de saber escolar, um conhecimento selecionado a partir de uma cultura social mais ampla, que passa por um processo de mediação didática, ao mesmo tempo em que é disciplinarizado, constituindo-se, assim, no embate com os demais saberes sociais e diferenciando-se dos mesmos (LOPES apud ALMEIDA; BARRETO FILHO, 2001). 


\section{Segunda Categoria: Manutenção do Movimento}

Quadro 4 - Unidades significantes oralizadas.

Expressões orais:

Neste caso, eu explicaria a inércia, a primeira lei. Todo corpo em movimento, ele continua em movimento, e todo corpo em repouso, fica em repouso, a menos que uma força interaja com ele. Então, ela se manteria em movimento, devido ao estado de inércia. Porque ela contém quantidade de movimento! Que é força! É ela que mantém o movimento da pedra. A força ocasionou o movimento; a partir daí, parou a ação da força, enquanto não perder a aceleração, ela continua viajando. Devido ao movimento que existe na pedra, ela tem a tendência de continuar o movimento na horizontal e na vertical. Ela vai perdendo a velocidade, devido à força de atrito "forças contrárias". Por que todo corpo tende a permanecer em movimento, retilíneo uniforme e para sempre, desde que tenha uma outra força atuando sobre este corpo. Pela primeira lei de Newton, daria esta explicação.

Quadro 5 - Unidades significantes escritas.

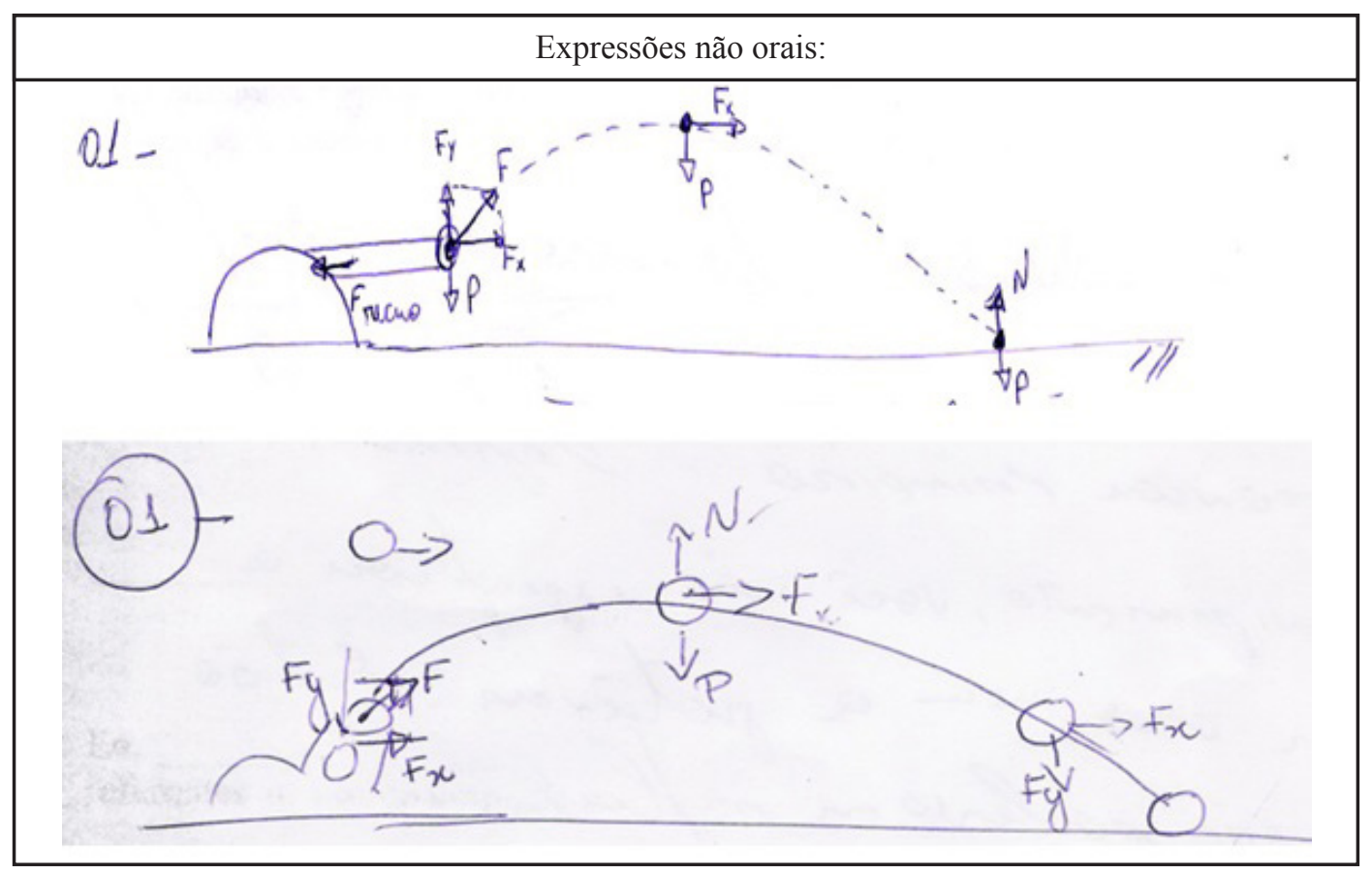

Das respostas contidas no quadro 3, observamos que os docentes, de modo geral, se ancoram no conceito de inércia, para explicar o porquê da continuidade do movimento de um corpo, após seu lançamento, e recorrem, também, ao conceito de força nessa manutenção, exemplos que ganham reforço nas figuras do quadro 4, no qual visualiza-se a suplementação de forças, no caso $\left(\mathrm{F}_{\mathrm{x}}\right)$, que mantém o objeto em movimento. Situações semelhantes foram constatadas no trabalho de Braz da Silva e Mazzotti (1998), no qual, os professores desfalcavam a Teoria newtoniana de sua Geometria, distorciam conceitos e suplementavam a Física com valores. É prudente salientar que, em nosso trabalho, não conseguimos detectar esses valores, pois, para isso, seria necessário ampliar o número de professores pesquisados. 


\section{Terceira Categoria: Elementos Condicionantes do Movimento}

\section{Quadro 6 - Unidades significantes oralizadas.}

Expressões orais:

Ela vai perdendo a velocidade, devido à força de atrito "forças contrárias". A aceleração da moto foi maior que a aceleração do carro. A aerodinâmica da moto?! A força de atrito do asfalto com o pneu vai ser menor, porque a área de contato da moto como o carro é bem menor! Então, a força de atrito que impede o movimento para o carro é maior... dificultando... Existe uma força de atrito contrária ao movimento, essa força depende da área de contato, então, se o carro tem uma área de contato maior, então, a força é maior. $\mathrm{O}$ atrito dificulta o movimento do carro mais que a moto. $\mathrm{O}$ arrancar, o sair mais rápido, está relacionado com o torque, o torque, o motor vai dar aos pneus, e isso está relacionado com a massa. Porque, mesmo que o torque seja o mesmo para os dois: moto e carro, a tendência da moto, pelo fato de ser mais leve, é adquirir uma aceleração maior. Devido à potência da moto?! Ou do acelerador? Do motorista? A pessoa acelera mais... porque o carro precisaria de mais força... e devido à quantidade de massa, também, considerando a massa (do carro) é maior que a da moto e precisa aplicar mais força. No caso da moto, a massa da moto é menor, então, vai ter uma aceleração maior. Depende da moto, da potência do equipamento. A moto sairia na frente, devido à massa do carro ser maior.

No quadro 5, vários fatores são apontados pelos professores como condicionantes para o movimento de objetos. De modo geral, os docentes se ancoraram no conceito de massa para diferenciar a aceleração entre corpos distintos. Como foi citado anteriormente, ancorar significa dar nome a alguma coisa, consiste em integrar ideias a um sistema de pensamento pré-existente. A objetivação, outro mecanismo gerador de representações, pode ser evidenciada, por exemplo, na frase: A pessoa acelera mais... porque o carro precisaria de mais força... e devido à quantidade de massa, também, considerando a massa (do carro), é maior que a da moto e precisa aplicar mais força. Como se pode notar, objetivar significa descobrir a qualidade icônica de uma ideia. É reproduzir um conceito em imagem.

\section{Considerações Finais}

Os resultados que obtivemos do pequeno grupo de oito professores de Física convergem para os resultados de Braz da Silva (1998) que investigou as Representações Sociais de Ciência Física do grupo social de professores entrevistados da cidade do Rio de Janeiro. Ou seja, Braz da Silva (1998) encontrou, em sua investigação, professores que, no ensino de Física de Newton, apoiavam-se em um realismo ingênuo. Essa também é a conclusão de nossa pesquisa.

Dos oito professores participantes, apenas um $\left(\mathrm{P}_{6}\right)$ apresentou uma representação social, razoavelmente, fiel à Física newtoniana. Ancorando-se em elementos da Física de Newton, $\mathrm{P}_{6}$ uniu as noções de força, massa, aceleração, inércia, velocidade e gravidade, em um contexto em que a Geometria não desapareceu e nem houve adição de novos valores. Os outros sete professores apresentaram noções da Física newtoniana que se ancoravam, ora em um conceito, ora em outro, adicionando valores e desvencilhando-se da Geometria. Estes sujeitos mantiveram suas explicações em exemplos rotineiros, que os levaram a uma representação que não condiz propriamente com a Física de Newton, isto é, distorceram a Física newtoniana. 
Uma possível hipótese para esse afastamento da Física newtoniana, encontrada nos sete professores, leva-nos a pensar nas representações da Física apresentadas em livros didáticos de Física que apresentam a Física de Newton sem a Geometria. Para Braz da Silva (1998), o livro didático representa a materialização ou a objetivação da Física que se quer ensinar. Ela assinala o percurso necessário para o seu aprendizado e, também, determina a prática pedagógica dos professores (BRAZ DA SILVA, 1998, p.103).

Como já dissemos no início deste trabalho, o docente passa por uma série de situações que o leva a agir desse ou daquele modo, ao reapresentar um determinado conhecimento escolar que é, então, transmitido ao aluno. Ao nos deter nesse processo que denominamos de recontextualização do saber, percebemos que sete professores entrevistados retiram da Física newtoniana sua Geometria e a realçam com outros valores. Braz da Silva (1998), nessa direção, salienta que seria de esperar que o contato com a Física (na escola), por meio de seu ensino, fosse capaz de ultrapassar este processo. Entretanto, o ensino da Física, por meio de seus agentes de difusão (professores, livros didáticos e métodos de ensino), apoia-se em uma representação, expressão desse mesmo processo, o que impede sua superação.

Na visão de Moscovici (1978), as crenças não científicas sustentam-se em inferências predominantemente valorativas. Nas ciências, os valores referem-se aos procedimentos da comunidade científica (punição por fraudes; atacar os argumentos e não o autor; revisão por pares), portanto, as inferências são apoiadas nos argumentos utilizados. Como a ciência Física, segundo o discurso do professor, aparece distorcida conceitualmente (concepções alternativas), desfalcada de estruturação geométrica, suplementada por valores éticos, o que se tem a considerar é transposição dos conhecimentos científicos para currículo escolar. Esse processo realiza-se por meio das situações de ensino-aprendizagem e envolvem os atores sociais deste contexto - alunos, professores, livro didático. Esses mecanismos de distorção, desfalque e suplementação do objeto social, constituem o processo de décalage, discutido por Jodelet (2001), o qual gera as representações sociais.

Em relação às situações de ensino-aprendizagem, torna-se necessário, portanto, estabelecer um diálogo entre os modelos didáticos que se difundem e circulam no ambiente escolar, o que implica desestabilizar certas concepções arraigadas, cujos significados estão ancorados na realidade social na qual a escola encontra-se inserida. Segundo Braz da Silva (1998), seria de se esperar que o contato com a Física, por meio de seu ensino, fosse capaz de ultrapassar este processo. Entretanto, esse ensino, mediante seus agentes de difusão, também, se apoia em uma representação, que chamamos de Física do cotidiano, que impede trabalhar com o modelo newtoniano. As próprias estratégias de ensino do cotidiano são obstáculos para a compreensão e o ensino de Física de Newton na escola.

\section{Referências}

ALEXANDRE, Marcos. O papel da mídia na difusão das representações sociais. Comum, Rio de Janeiro, v.6, n. 17, p. 111-125, jul./dez. 2001.

ALMEIDA, Maria José P. M. de; BARRETO FILHO, Benigno. Um diálogo com trabalhos sobre experimentação nas ciências do ensino fundamental. In: ENCONTRO NACIONAL DE PESQUISA EM EDUCAÇÃO EM CIÊNCIAS, 3., 2001, Atibaia. Anais... Atibaia, 2001.

ARRUDA, Angela. Teoria das representações sociais e teorias de gênero. Caderno de Pesquisa, São Paulo, v. 3, n. 117, p. 127-147, 2002.

BARDIN, L. Análise de conteúdo. Tradução de L. A. Reto e A. Pinheiro. Lisboa: Martins Fontes, 1977.

BAUER, Martin. Popularização da ciência como "imunização cultural": a função de resistência das representações sociais. In: GUARESCHI, Pedrinho A.; JOVCHELOVITCH, Sandra (Org.). Textos em 
Representações Sociais. 3. ed. Petrópolis: Vozes, 1997.

BRAZ DA SILVA, Alcina Maria Testa. Representações sociais: uma contraproposta ao estudo das concepções alternativas no ensino da física. 1998. Tese (Doutorado) - Universidade Federal do Rio de Janeiro, Rio de Janeiro.

BRAZ DA SILVA, Alcina Maria Testa; MAZZOTTI, Tarso Bonilha. Física do cotidiano: um elemento nuclear na representação social de ciência Física. 1998. Disponível em: <http://web.mac.com/ tmazzotti.Web/Eloquentia>. Acesso em: 20 jan. 2011.

BURTT, Edwin Arthur. As bases metafísicas da física moderna. Tradução de José Viegas Filho e Orlando Araújo Henriques. Brasília: Ed. UnB, 1983.

GUARESCHI, Pedrinho A. Sem dinheiro não há salvação: ancorando o bem e o mal entre neopentecostais. In: GUARESCHI, Pedrinho A.; JOVCHELOVITCH, Sandra (Org.). Textos em representações sociais. 3. ed. Petrópolis: Vozes, 1997.

JODELET, Denise. As representações sociais: um domínio em expansão. In: (Org.). As representações sociais organizadora. Tradução de Lílian Ulup. Rio de Janeiro: Ed UERJ, 2001. p. 1744.

LOPES, Alice Casimiro. Organização do conhecimento escolar: analisando a disciplinaridade e a integração. In: CANDAU, V. M. (Org). Linguagem, espaços e tempos no ensinar e aprender. Rio de Janeiro: DP\&A, 2000. p. 147-163.

MOSCOVICI, Serge. Das representações coletivas às representações sociais: elementos para uma história. In: JODELET, Denise (Org.). As representações sociais. Tradução de Lílian Ulup. Rio de Janeiro: EDUERJ, 2001. p. 45-66.

MOSCOVICI, Serge. Representações sociais: investigações em psicologia social. Tradução de Pedrinho A. Guareschi. Petrópolis: Vozes, 2003.

A representação social da psicanálise. Rio de Janeiro: Zahar, 1978.

PITOMBO, Luiz Roberto de M.; SILVA, Marcolina Aparecida E. Como os Alunos entendem a queima e combustão: contribuições a partir das representações sociais. Química Nova na Escola, São Paulo, v. 1, n. 23, p. 18-21, 2006.

QUEIROZ, Glória. O professor artista-reflexivo de física, a pesquisa em ensino de física e a modelagem analógica. Revista da Associação Brasileira de Pesquisa em Educação em Ciências, São Paulo, v. 1, n. 3, p. 86-99, 2001.

SÁ, Celso P. Representações Sociais: o conceito e o estado atual da Teoria. In: SPINK, Mary Jane (Org.). $O$ conhecimento no cotidiano: as representações sociais na perspectiva da psicologia social. 2. ed. São Paulo: Brasiliense, 1995. p. 19-45.

SEMIN, Gun R. Protótipos e representações sociais - As representações sociais. In: JODELET, Denise (Org.). As representações sociais. Tradução de Lílian Ulup. Rio de Janeiro: EdUERJ, 2001. p. 205216.

\section{Anexo 1}

\section{Questionário}

a) perguntas da primeira parte do questionário (Entrevista):

01 - Você está em sala de aula e está explicando a Física newtoniana aos seus alunos. Como você explicaria o porquê de uma pedra continuar a se mover mesmo depois que a mão que a lançou não a tocar mais?

02 - Na aula surge o seguinte questionamento: se o Sol, de repente, desaparecesse, o que aconteceria com o planeta Terra? Como você explicaria este fenômeno aos seus alunos?

03 - Um aluno observou um carro e uma motocicleta parados em um semáforo. Notou que a moto arrancou antes do carro quando o semáforo abriu. Como você explicaria esse fenômeno ao seu aluno?

04 - De acordo com a lei da Gravitação Universal, a Lua atrai a terra com uma força de mesma intensidade com que a Terra atrai a Lua. Por que esta não se choca contra a Terra? 
b) questões da segunda parte (Lápis e papel):

05- Imagine um tiro de canhão. Durante os três momentos da trajetória da bala (na boca do canhão, no meio da trajetória, e no ponto de chegada), quais são as forças envolvidas? Desenhe-as.

06 - A Lua está girando ao redor da Terra. Este fenômeno está ligado a alguma lei de Newton? Se sim, diga qual (is) é (são) e explique como ela(s) atua(m).

07 - Você poderia elencar (enumerar - pelo menos cinco) fenômenos (situações) nos quais as leis de Newton sejam aplicáveis?

08 - Por que os astronautas flutuam no interior de uma nave espacial? 
Barbosa, R. G.; Bellini, M.; Silva, A. M. T. B. 